

\title{
Are Prosodic Variants Stored in the French Mental Lexicon?
}

Amandine Michelas, Sophie Dufour

\section{To cite this version:}

Amandine Michelas, Sophie Dufour. Are Prosodic Variants Stored in the French Mental Lexicon?.

Experimental Psychology, 2019, 66 (6), pp.393-401. hal-02413004

\section{HAL Id: hal-02413004 \\ https://hal.science/hal-02413004}

Submitted on 6 Jan 2020

HAL is a multi-disciplinary open access archive for the deposit and dissemination of scientific research documents, whether they are published or not. The documents may come from teaching and research institutions in France or abroad, or from public or private research centers.
L'archive ouverte pluridisciplinaire HAL, est destinée au dépôt et à la diffusion de documents scientifiques de niveau recherche, publiés ou non, émanant des établissements d'enseignement et de recherche français ou étrangers, des laboratoires publics ou privés. 
Running title: stress representation in French

Are prosodic variants stored in the French mental lexicon?

Amandine Michelas ${ }^{1}$ and Sophie Dufour ${ }^{1}$

Laboratoire Parole et Langage, CNRS \& Aix-Marseille University, Aix-en-Provence, France amandine.michelas@lpl-aix.fr; sophie.dufour@lpl-aix.fr

\footnotetext{
${ }^{1}$ Both authors contributed equally to the paper.
} 


\begin{abstract}
A long-term priming experiment examined the way stress information is processed and represented in French speakers' mind. Repeated prime and target words either matched (/bã'do/ /bã'do/ 'headband') or mismatched their stress pattern (/bãdo/ - /bã'do/). In comparison to a control condition (/mas ̃̃/ - /bã'do/), the results showed that matching and mismatching primes were equally effective in facilitating the processing of the target words. Thus, despite the fact that French speakers routinely produce and hear words in their stressed and unstressed versions, this study suggests that stress in French is not integrated into lexical representations.
\end{abstract}

Keywords: Spoken word recognition, lexical representations, French prosody, primary stress. 
Regarde le joli la'pin! 'Look at the pretty bunny' or Regarde le lapin 'noir! 'Look at the black bunny'. In French, a same word (e.g. LAPIN 'bunny') either receives primary stress or doesn't depending on its place within the accentual phrase. In particular, a word is stressed when it corresponds to the last full syllable of the accentual phrase. Consequently, French speakers continuously produce words in both their stressed and unstressed versions and are routinely exposed to both versions in everyday conversational exchanges. How many LAPIN versions are stored in French speakers' minds? Are words stored in various prosodic forms in the French mental lexicon? This is precisely the question under investigation. This is an important endeavor, because while studies have examined how French speakers perceive stress patterns that do not respect the stress placement rules in French (e.g. Dupoux, Pallier, Sebastián \& Mehler, 1997), to the best of our knowledge, to this date, no study has examined the way French speakers represent allowed stress patterns in French.

In a seminal study examining how French speakers perceive stress information, Dupoux et al. (1997) reported that these speakers experience difficulties discriminating between stimuli that differ in the position of stress. In an $\mathrm{ABX}$ task, in which $\mathrm{A}, \mathrm{B}$ and $\mathrm{X}$ were spoken by three different speakers, and in which participants judged whether X was identical to A or to B, Dupoux et al. (1997) showed that compared to Spanish speakers, French speakers had more difficulties discriminating between two nonsense words that differed only in stress position ('fidape, fi'dape,). In addition, French speakers performed worse when the stimuli differed in stress ('fidape, fi'dape) than in phoneme ('fidape, 'lidape). However, a more recent study (Michelas, Esteve-Gibert and Dufour, 2018) indicates that French speakers' difficulties in using stress information is specific to stimuli that do not respect stress placement rules in French. In Dupoux et al. (1997), first vs. second stressed syllables ('fidape, fi'dape) and second vs. third stressed syllables (fi'dape, fida'pe) were 
used, but in French, a word cannot receive primary stress at any non-final position. Using the same paradigm as Dupoux et al., Michelas et al. (2018) also showed that French speakers had more difficulty discriminating between two French words that differed in stress location (/'зуві/-/зу'иі/) compared to words that differed in one phoneme (/зу'ког/-/зу' кі/ 'swearword-jury'). Crucially, no difficulty was observed when the stimuli differed in the presence vs. absence of stress (/зуві//зу'ьі/), namely on a stress contrast frequently encountered in French. In this specific condition, French speakers performed equally well on a stress (/зуві/-/зу' ві/) and on a phoneme (/зу'иг̃ //зу'ьі//) difference. Such observation suggests that French speakers are fully capable of discriminating an unstressed word from its stressed counterpart, but they experience difficulty establishing categories based on stress location probably because it does not exist in French.

Other studies have shown that French speakers use the presence/absence of stress to segment continuous speech stream into words (Bagou \& Frauenfelder, 2018; Christophe, Peperkamp, Pallier, Block, \& Mehler, 2004; see also Spinelli, Welby \& Schaegis, 2007; Spinelli, Grimault, Meunier \& Welby, 2010 for secondary stress). Christophe et al. (2004), asked participants to detect a target word (e.g. CHAT 'cat') in sentences like [Le CHAT grin'cheux] 'the grumpy cat' in which only the word grincheux 'grumpy' is stressed or in sentences like [Le 'CHAT] [grim'pait] 'the cat was climbing up' in which both the words chat and grimpait are stressed. They found slower detection times in [Le CHAT grin'cheux] than in [Le 'CHAT] [grim'pait]. The slower detection of CHAT in [Le CHAT grin'cheux] has been interpreted as resulting from competition between CHAT and its competitor chagrin 'sadness'. In this case, since there is no stress on CHAT to indicate its end, the word chagrin remains active and competes with the word CHAT. The results of Christophe et al.'s suggest that French speakers insert a word-final 
boundary each time they encounter a stressed syllable. It appears thus that the presence of stress in French boosts lexical segmentation by preventing the activation of inappropriate lexical candidates.

Because French speakers use stress information both to categorize words as being stressed or unstressed (Michelas et al., 2018) and to locate word boundaries, the question under investigation in the current study is whether French speakers encode stress information in their lexical representations. Indeed, since French speakers routinely produce and hear words in their stressed and unstressed versions, models assuming the storage of multiple variants for a same word either in an abstract way (Connine, Ranbom \& Patterson, 2008) or in the form of detailed acoustic traces (Goldinger, 1998) predict that words in French could be stored both in their stressed and unstressed forms.

We used the long-term priming paradigm which is a well-established procedure to probe the functional architecture of the mental lexicon and processes involved in spoken word recognition (Dufour \& Nguyen, 2014; Dufour \& Nguyen, 2017; McLennan \& Luce, 2005; McLennan, Luce \& Charles-Luce, 2003; Monsell \& Hirsh, 1998; Sumner \& Samuel, 2009). Word repetition effects as well as more subtle priming effects among phonologically similar words have been obtained using this procedure. Here, we focused on the long-term repetition priming effect. Typically, in this kind of paradigm, participants are presented with two blocks of stimuli, the first consisting of the primes, and the second consisting of the targets. During the second block, some of the words from the first block are repeated and the others consist in new words. The repetition priming effect refers to facilitation in the processing - i.e. decrease in reaction times (RTs) - for the target words encountered for a second time, and has been interpreted as being due to the repeated activation of the same form-based representation in memory. Numerous studies have shown that the long-term repetition priming effect is sensitive to both phonemic and subphonemic variation in the way words 
are pronounced due to, one the one hand, dialectal accent (Sumner \& Samuel, 2009) and allophonic variation (McLennan et al., 2003), and on the other hand, to speaker identity (Dufour \& Nguyen, 2014; McLennan \& Luce, 2005) and speech rate (McLennan \& Luce, 2005). In their study, McLennan et al. (2003) focused on phonological variation in the way words are pronounced and examined how flap is processed and represented in memory. In American English when $/ \mathrm{t} / \mathrm{or} / \mathrm{d} /$ occurs between two vowels as in butter or paddy, they are realized as a flap $(/ \mathrm{r} /)$, a segment that is neither $/ \mathrm{t} / \mathrm{nor} / \mathrm{d} /$. In a lexical decision task, the authors reported a clear repetition priming effect, in comparison to a control condition, when the primes and targets were identical (e.g. [b^rə]$[b \Lambda r x] ;[b \Lambda t r]-[b \Lambda t r])$. No significant priming effect was observed when the primes and the targets mismatched $([\mathrm{b} \Lambda \mathrm{t} \gamma]-[\mathrm{b} \Lambda \mathrm{r} \cdot])$ in the intervocalic segment realization. The lack of a priming effect when the prime was $\left[b_{\Lambda} t \gamma\right]$ and the target was $\left[b_{\Lambda} \curvearrowright \gamma\right]$ and vice versa suggested that two different lexical representations were activated by $[\mathrm{b} \Lambda \curvearrowright \gamma]$ and $[\mathrm{b} \Lambda \mathrm{t} \gamma]$. Sumner and Samuel (2009) examined the way phonological variation that comes from dialectal accent is processed and represented in NewYork city (NYC) dialect speakers who systematically produce an r-less variant of -er final words, but who are regularly exposed to General American (GA). The results of a long-term priming experiment showed that both GA final r-full primes (slend $[\curvearrowright])$ and $\mathrm{NYC}$ final r-less primes (slend[ə]) facilitated responses to both GA final $\mathrm{r}$-full targets (slend[ə]$]$ ) and NYC final r-less targets (slend[ə]) in NYC dialect participants. Nonetheless, the magnitude of these facilitation priming effects was smaller than that observed in the case of repeated prime and target pairs (GA primes and targets and NYC primes and targets). Such observation suggests that slend[ə] only partially activated the lexical representation corresponding to slend $[\ngtr]$ and vice versa, and that two distinct lexical representations were fully activated by slend[ə] and slend[ə].

Other studies using the long-term repetition priming paradigm have shown that more subtle variation in the way a particular word is pronounced, related to speaker identity or speech rate, also 
affects the way the spoken word is processed and represented (Dufour \& Nguyen, 2014; McLennan \& Luce, 2005). In a lexical decision task in which non-words were wordlike, McLennan \& Luce (2005) manipulated speech rate in one experiment and speaker identity in another experiment. Repeated prime and target words either matched or mismatched in speech rate or speaker identity. In comparison to unrelated prime-target pairs, both match and mismatch primes were effective in facilitating the subsequent processing of the target words. Nonetheless, a significant difference between match and mismatch primes, with slower RTs in the mismatch priming condition, indicated that both types of prime were not equally effective in priming the target words. Such a diminution in the magnitude of the repetition priming effect when repeated primes and targets were pronounced by different speakers, was also reported for low-frequency words in Dufour and Nguyen (2014).

Altogether, the aforementioned studies indicate that the long-term priming paradigm is well-suited to examine whether words are represented in the multiple forms they take. Based on the logic behind the long-term repetition priming effect, we examined whether the regular production and exposure to French words in both their stressed and unstressed forms have led to the creation of distinct lexical representations. In our study, words were repeated either in the same stress pattern (e.g., /bã'do/ - /bã'do/, bandeau 'headband') or in a different stress pattern /bãdo/ /bã'do/). We reasoned that if the different prosodic forms that French speakers produce are represented distinctly in the mental lexicon, then the presentation of one variant would not fully activate the other variant because there isn't an exact match between the information present in the input of one variant and the lexical representation associated with the other variant. As a result, a diminution in the magnitude of the repetition priming effect should be observed when the repeated primes and targets mismatch on their stress pattern. 
Participants: Forty-eight native speakers of French between 18 and 45 years old participated in the experiment. Each participant gave informed consent prior to the experiment. They all reported having no hearing or speech disorders.

Material: Forty-eight words with a CVCV disyllabic structure were selected from Lexique, a lexical database of the French language (New, Pallier, Ferrand, Matos, 2001) and were used both as primes and targets. They have a mean frequency of 7.60 occurrences per million. 16 additional words with the same syllabic structure were selected and used as control primes. They have a mean frequency of 6.96 occurrences per million. The words are given in Appendix 1.

In order to obtain the stressed and unstressed versions of the stimuli, we asked a native speaker of French to produce the 64 words within carrier sentences in which the target word bore stress on its last syllable or was unstressed depending on its position within the Accentual Phrase (AP) (e.g. On m'avait parlé [d'un bandeau 'bleu] $]_{A P}$ qui était joli 'I had been told about a blue headband which was pretty' vs. On m'avait parlé [d'un petit ban'deau $]_{A P}$ qui était joli 'I had been told about a small headband which was pretty'). To avoid coarticulation effects due to contextualized-speech, each word was first extracted from its carrier sentence and then auditorily presented to the speaker in isolation. The speaker had to repeat each word in its stressed and unstressed versions. The 128 tokens thus obtained were recorded at a sampling frequency of 44 $100 \mathrm{~Hz}$, segmented and then normalized in intensity at a level of $70 \mathrm{~dB}$ SPL. 
Acoustic analyses were then conducted using Praat software (Boersma \& Weenink, 2015) to ensure that the words were produced with the expected stress patterns. Pre-boundary lengthening and fundamental frequency (f0) rises, the two main correlates of primary stress in French, were measured and are summarized in Table 1. Since our words were CV/CV disyllabic words, the boundary between both syllables was hand-located at the end of the first vowel inspecting both waveforms and spectrograms. f0 minima and maxima associated to the two syllables were located using Praat commands. Note that in order to minimize microprosodic effects due to voiceless gaps, the words were selected so that the two syllables began with a voiced consonant. Duration and f0 values were then automatically extracted using Praat scripts. As expected, the final syllable of the target words was longer $(\mathrm{t}(47)=17.73, \mathrm{p}<.0001)$ and associated with a stronger f0 rise $(\mathrm{t}(47)=$ $21.26, \mathrm{p}<.0001)$ than the first syllable only in their stressed versions. The average duration of the target words was 381 and $287 \mathrm{~ms}$, respectively in their stressed and unstressed versions. Figure 1 illustrates the word bandeau 'headband' produced in its unstressed version [bãdo] then with a primary stress on its last syllable [bã'do].

\section{INSERT TABLE 1 AND FIGURE 1}

For the purpose of the lexical decision task, 64 disyllabic pseudo-words with a CVCV structure were created by changing the last phoneme of real words not previously used (e.g. /bezi/ created from the word /beze/ 'kiss'). This allowed us to have wordlike non-words, and to constrain the participants to listen to the stimuli up to the end prior to giving their response. The non-words followed the same criteria as the words and were thus recorded and produced in their stressed (e.g. /be'zi/) and unstressed (e.g. /bezi)/ versions. 
Design: Two blocks of stimuli were presented. The first one consisted of the primes and the second one of the targets. Within each block, half the stimuli were stressed, and the other half were unstressed. The target block consisted of 48 target words and 48 pseudo-words. Among the 48 target words, 16 served in the matched priming condition, 16 in the mismatched priming condition and 16 in the control priming condition. Within each priming condition, half the target words were presented in their stressed version, and the other half were presented in their unstressed version. The prime block also consisted in 48 words and 48 pseudo-words. Among the prime words, 16 consisted in the repetition of the targets with the same stress pattern (e.g. /bã'do/ - /bã'do/), 16 consisted in the repetition of the targets with a different stress pattern (e.g. /bãdo/ - /bã'do/), and the 16 others were the control primes and were unrelated to the targets. Among the control primes, half of them were presented in their stressed version and the other half were presented in their unstressed version. As for the pseudo-words, 16 consisted in the exact repetition (with the same stress pattern) of the pseudo-words used in the target block, 16 consisted in the repetition of the pseudo-words used in the target block but with a different stress pattern, and 16 were unrelated.

Because each target word was paired with three different primes (match, mismatch, control) and no participant was presented with the same target twice, three experimental lists were created. The three lists were then divided into two sub-lists so that each stimulus of the prime and target blocks was heard in its stressed and unstressed versions.

Procedure: The participants were tested individually in a sound attenuated booth, and the stimuli were presented over calibrated headphones at $70 \mathrm{~dB}$. Stimulus presentation and recording of the data were controlled by a PC running the E-Prime software (version 2.0, Psychology 
Software Tools). In both the prime and the target blocks, participants were asked to make a lexical decision as quickly and accurately as possible with "word" responses using their dominant hand on a button-box that was placed in front of them. Response times (RTs) were recorded from the onset of stimuli. Within each block, the stimuli were presented randomly. An inter-trial of $2000 \mathrm{~ms}$ elapsed between the participant's response and the presentation of the next stimulus. The participants were tested on only one experimental list and they began with 12 practice trials.

\section{Results and discussion}

Data are available at the Open Resources and Tools for Language (ORTOLANG) repository: https://hdl.handle.net/11403/expepsycho_michelasdufour. Statistical analyses were performed on the target words. Four items that gave rise to an error rate of more than $40 \%$ were removed from the analyses. RTs analysis was performed on correct responses, thus removing 228 data $(10.8 \%$ ) out of 2112 data. 6 outliers (one RT $=372 \mathrm{~ms}$ and the other five $>2000 \mathrm{~ms}$ ) were also excluded from the analysis. The mean RT and percentage of correct responses in each condition are presented in Figure 2. RTs were analyzed using a linear mixed-effect regression model (lme4 package in R-studio statistics Version 1.1.456). For the model to meet the assumptions of normally-distributed residuals and homogeneity of the variance, a log transformation was applied to RTs. The model was run on 1878 data points. The model included prime type (match, mismatch, control) as fixed effect, participants and items as random intercepts and random slopes by participant and by item.

\section{INSERT FIGURE 2}


With the control prime condition as intercept, the model revealed that RTs were faster for target words preceded by match primes than for target words preceded by control primes $(\beta=$ $0.09, \mathrm{SE}=0.01, \mathrm{t}=-7.44, \mathrm{p}<.0001) . \mathrm{RTs}$ were also faster for target words preceded by mismatch primes than for target words preceded by control primes $(\beta=-0.09, \mathrm{SE}=0.01, \mathrm{t}=-6.54, \mathrm{p}<.0001)$. To test the difference between the match and the mismatch conditions, the model was releveled so that the match prime condition was the intercept. Critically, no difference was observed between the match and mismatch prime conditions $(\beta=0.01, \mathrm{SE}=0.01, \mathrm{t}=0.45, \mathrm{p}>.20)$.

Accuracy data $(1=$ correct responses, $0=$ incorrect responses $)$ was analyzed using a mixedeffect regression model with a logistic linking function. The model was run on 2112 data points. It included prime type (match, mismatch, control) as fixed effect, participants and items as random intercepts and random slopes by participant and by item. With the control prime condition as intercept, the model revealed that participants gave more correct responses for target words preceded by match primes than for target words preceded by control primes $(\beta=-1.04, \mathrm{SE}=0.28$, $\mathrm{z}=-3.70, \mathrm{p}<.001)$. Participants also gave more correct responses for target words preceded by mismatch primes than for target words preceded by control primes $(\beta=-1.00, \mathrm{SE}=0.24, \mathrm{z}=-4.14$, $\mathrm{p}<.0001)$. To test the difference between the match and the mismatch conditions, the model was releveled so that the match prime condition became the intercept. Critically, no difference was observed between the match and mismatch prime conditions $(\beta=0.04, \mathrm{SE}=0.30, \mathrm{z}=0.12, \mathrm{p}>$ $.20)$.

To sum-up, our study suggests that match and mismatch primes were equally effective in facilitating the processing of the target words. A possibility, however, is that the long-term priming 
paradigm is not sensitive enough to detect a difference in the size of the priming effect across match and mismatch conditions. Despite substantial studies suggesting that it is rather unlikely (Dufour \& Nguyen, 2014; McLennan et al., 2003; McLennan \& Luce, 2005; Sumner and Samuel, 2009), we ran a control experiment to provide further demonstration that this paradigm is well-suited to probe the activation of different lexical representations. This control experiment focused on another type of variation, and in particular on segmental variation coming from regional accents. In Southern French, there is no contrastive distinction between /o/ and /o/ (e.g. cote 'hill' /kot/ vs. cote 'rating' /kst/ in Standard French), and Southern French is said to have one back mid vowel phoneme only, whose phonetic realization as a mid-high [o] or mid-low [o] is entirely governed by the structure of the carrier syllable: it is mid-high in open syllables and mid-low in closed syllables. As a result, the word mauve "mauve" pronounced [mov] by Standard French speakers is pronounced [mov] by Southern French speakers. Because Southern French speakers are regularly exposed to Standard French pronunciations via the media and/or interactions with speakers of other French areas, some studies (Dufour, Nguyen \& Frauenfelder, 2007; Dufour, Chuang \& Nguyen, 2019) suggest that these speakers are likely to have created two lexical representations for the words mauve, the one corresponding to the Standard French variant (/mov/), and the other one corresponding to their own variant (/mov/). Thus, in this control experiment using exactly the same procedure as in the main experiment, we tested whether the magnitude of the long-term repetition priming effect modulates as a function of a segmental mismatch between two lexical forms. Because regional variation is not the focus of the present paper, the experiment is described in Appendix 2. Overall, the results revealed a significant difference between the match (/mov/-/mov/) and mismatch conditions (/mov/-/mov/). Thus, our failure to find a significant difference between the match and mismatch primes in the main experiment is probably not due to a lack of sensitivity of the paradigm. Rather, the null effect between the match and mismatch primes is probably due 
to the fact that it is the same form-based representations that have been activated by the two prosodic variants. 


\section{General discussion}

In the French language, the presence of stress within words has no consequence for their meaning. However, French speakers routinely produce and encounter words either in their unstressed version (/bãdo/) or in their stressed version (/bã'do/) according to their place within the accentual phrase. Given that stress in French guides lexical segmentation (Bagou \& Frauenfelder, 2018; Christophe et al., 2004), we examined here whether or not stress information influences spoken word recognition. We found a clear repetition priming effect both when the repeated primes and targets matched and when they mismatched in their stress patterns. More crucially, match and mismatch primes were equally effective in facilitating target word processing. Such an observation thus suggests that the same form-based lexical representation associated to the target words has been activated by both match and mismatch primes. More importantly, despite the fact that French speakers routinely produce and hear words in their stressed and unstressed versions, this study suggests that stress in French is not integrated into lexical representations.

Our findings thus argue in favor of the storage of only one lexical representation for the multiple prosodic variants that French words take. On the contrary, our control experiment as well as other studies examining the representation and processing of regional variants (Dufour et al., 2019; Sumner \& Samuel, 2009) or the schwa vowel (Connine et al., 2008) clearly support the view of a mental lexicon composed of multiple variants for a word (Connine et al., 2008). For example, Connine et al. (2008) examined the way American listeners recognize words containing the schwa vowel deletion in post-stress environment (corporate vs. corp'rate). Participants had to perform a lexical decision task on both with-schwa and without-schwa versions of words while variant production frequency was manipulated (high deletion rate/low deletion rate). For without-schwa 
variants, participants responded faster for words with high deletion rate than for words with low deletion rate. The authors concluded that the two variants of the word corporate, the one with the schwa vowel and the other one without the schwa vowel are stored in the mental lexicon of American English listeners with their respective frequency. These results suggest that the different pronunciations of a word lead to the creation of multiple lexical representations, the one corresponding to the /' ks:rporət/ form and the other corresponding to the 'ks:rprət/ form. A way to reconcile multiple variants storage modeling with our findings related to prosodic variants is to consider that lexical representations rely more on segmental than supra-segmental information. As a result, stress variation could be encoded in the lexical representations only when it is lexically contrastive (e.g. Soto-Faraco, Sebastián-Gallés \& Cutler, 2001 for Spanish). Since stress information is not lexically distinctive in French, we cannot bring support to this class of models when we focus on stress variation.

There is however substantial evidence that lexically-irrelevant acoustic cues, related for example to speaker identity or speaking rate, are encoded along with phonological information, and affect spoken word recognition (Dufour \& Nguyen, 2014; McLennan \& Luce, 2005). The integration of lexically-irrelevant information is possible within exemplar-based models of spoken word recognition (Goldinger, 1998; Hintzman, 1986). Such models offer a view of the mental lexicon consisting in multiple acoustic traces that encode perceptual and contextual details associated to each individual occurrence of a word. Word recognition consists in finding the nearest match in this vast collection of exemplars. Because in these models each word is associated with multiple acoustic traces encoding fined-grained acoustic information, and because French words are associated to both a lengthening of their last syllable and a typical f0 rise when they are stressed, variation in stress pattern could be encoded in the same way as related-speaker variation has been 
shown to be encoded. However, stress in French is only cued by two main acoustic cues (lengthening of the syllable, and f0 rise). One possibility is that the cues signalling the presence vs. absence of stress in French are not as acoustically salient as speaker information such as gender differences which are cued by a large set of acoustic indices (e.g., f0 mean, f0 range, vocalic duration, VOT, formants, breathiness). Consequently, stress cues in French don't get mapped onto lexical representations and play no role in spoken word recognition. However, as we have seen, the cues signalling the presence vs. absence of stress are successfully used by French speakers in lexical segmentation tasks (Christophe et al., 2004) as well as in discrimination tasks (Michelas et al., 2018), thus making less likely that the lack of salience of stress cues is responsible of the fact that they are not coded in the lexicon. Therefore, our study examining the use of acoustic cues other than those related to speaker specificities poses some problems for exemplar-based models of spoken word recognition, and constitutes a new challenge for this kind of framework which has to explain why some sort of acoustic variants are stored and others not.

In conclusion, our study suggests that all word forms that speakers routinely produce and hear are not necessarily stored in the mental lexicon and used during word recognition. Our study also points out that it is not because listeners use certain cues present in the speech signal to perform one task (e.g. ABX task) that they necessarily use these cues to perform another task (e.g. lexical decision). Therefore, the ability of listeners to use speech cues thus needs to be tested through a wide variety of tasks. 


\begin{abstract}
Acknowledgements
This work was supported by the Labex Brain and Language Research Institute (ANR-11-LABX0036) and has benefited from the support of the French National Agency of Research (ANR), under the project title "Investments of the Future" A*MIDEX (ANR-11-IDEX-0001-02). We are grateful to Arthur Samuel and one anonymous reviewer for their helpful comments on earlier versions of the manuscript.
\end{abstract}




\section{References}

Boersma, P., \& Weenink, D. (2015). Praat. Doing phonetics by computer (Version 5.4.01, 2015), Computer program. Retrieved from www.praat.org.

Bagou, O., \& Frauenfelder, U. H. (2018). Lexical Segmentation in Artificial Word Learning: The Effects of Converging Sublexical Cues. Language and speech, 61(1), 3-30.

Christophe, A., Peperkamp, S., Pallier, C., Block, E., \& Mehler, J. (2004). Phonological phrase boundaries constrain lexical access I. Adult data. Journal of Memory and Language, 51(4), 523-547.

Connine, C. M., Ranbom, L. J., \& Patterson, D. J. (2008). Processing variant forms in spoken word recognition: The role of variant frequency. Perception \& Psychophysics, 70(3), 403-411.

Dufour, S., Chuang, Y. Y. , Nguyen, N. (2019): The processing of dialectal variants: Further insight from French. Applied Psycholinguistics, 40(2), 351-372.

Dufour, S., \& Nguyen, N. (2014). Access to talker-specific representations is dependent on word frequency. Journal of Cognitive Psychology, 26(3), 256-262.

Dufour, S., \& Nguyen, N. (2017). Does Talker-Specific Information Influence Lexical Competition? Evidence From Phonological Priming. Cognitive science, 41(8), 2221-2233.

Dufour, S., Nguyen, N., \& Frauenfelder, U. H. (2007). The perception of phonemic contrasts in a non-native dialect. The Journal of the Acoustical Society of America, 121(4), EL131EL136.

Dupoux, E., Pallier, C., Sebastián, N., \& Mehler, J. (1997). A destressing “deafness” in French?, Journal of Memory and Language, 36, 406-421.

Goldinger, S. D. (1998). Echoes of echoes? An episodic theory of lexical access. Psychological review, 105(2), 251-279. 
Hintzman, D. L. (1986). " Schema abstraction" in a multiple-trace memory model. Psychological review, 93(4), 411.

McLennan, C. T., \& Luce, P. A. (2005). Examining the time course of indexical specificity effects in spoken word recognition. Journal of Experimental Psychology: Learning, Memory, and Cognition, 31(2), 306.

McLennan, C. T., Luce, P. A., \& Charles-Luce, J. (2003). Representation of lexical form. Journal of Experimental Psychology: Learning, Memory, and Cognition, 29(4), 539.

Michelas, A., Esteve-Gibert, N., \& Dufour, S. (2018). On French listeners' ability to use stress during spoken word processing. Journal of Cognitive Psychology, 30(2), 198-206.

Monsell, S., \& Hirsh, K. W. (1998). Competitor priming in spoken word recognition. Journal of Experimental Psychology: Learning, Memory, and Cognition, 24(6), 1495.

New, B., Pallier, C., Ferrand, L., \& Matos, R. (2001). Une base de données lexicales du français contemporain sur internet: LEXIQUE. L'année Psychologique, 101(3), 447-462.

Soto-Faraco, S., Sebastián-Gallés, N., \& Cutler, A. (2001). Segmental and suprasegmental mismatch in lexical access. Journal of Memory and Language, 45, 412-432.

Spinelli, E., Welby, P., \& Schaegis, A. L. (2007). Fine-grained access to targets and competitors in phonemically identical spoken sequences: the case of French elision. Language and cognitive processes, 22(6), 828-859.

Spinelli, E., Grimault, N., Meunier, F., \& Welby, P. (2010). An intonational cue to word segmentation in phonemically identical sequences. Attention, Perception, \& Psychophysics, 72(3), 775-787.

Sumner, M., \& Samuel, A. G. (2009). The effect of experience on the perception and representation of dialect variants. Journal of Memory and Language, 60(4), 487-501. 
Table 1. Acoustic characteristics of target words in their stressed and unstressed versions.

\begin{tabular}{ccccc}
\hline & \multicolumn{2}{c}{ Unstressed version } & \multicolumn{2}{c}{ Stressed version } \\
\hline & $1^{\text {st }}$ syllable & $2^{\text {nd }}$ syllable & $1^{\text {st }}$ syllable & $2^{\text {nd }}$ syllable \\
\hline Syllable duration $(\mathrm{ms})$ & 144 & 143 & 142 & 239 \\
f0 minimum* $(\mathrm{Hz})$ & 187 & 176 & 182 & 171 \\
f0 maximum* $(\mathrm{Hz})$ & 181 & 174 & 178 & 402 \\
f0 rise $(\%)$ & -3 & -1 & -2 & 136 \\
\hline
\end{tabular}

* For unstressed syllables, the minimum and maximum f0 values correspond to the values associated to the beginning and the end of the f0 plateau. 
Figure 1. Phonemic and prosodic profile of the target word bãdo/ 'headband' in its unstressed (a) and stressed (b) version.

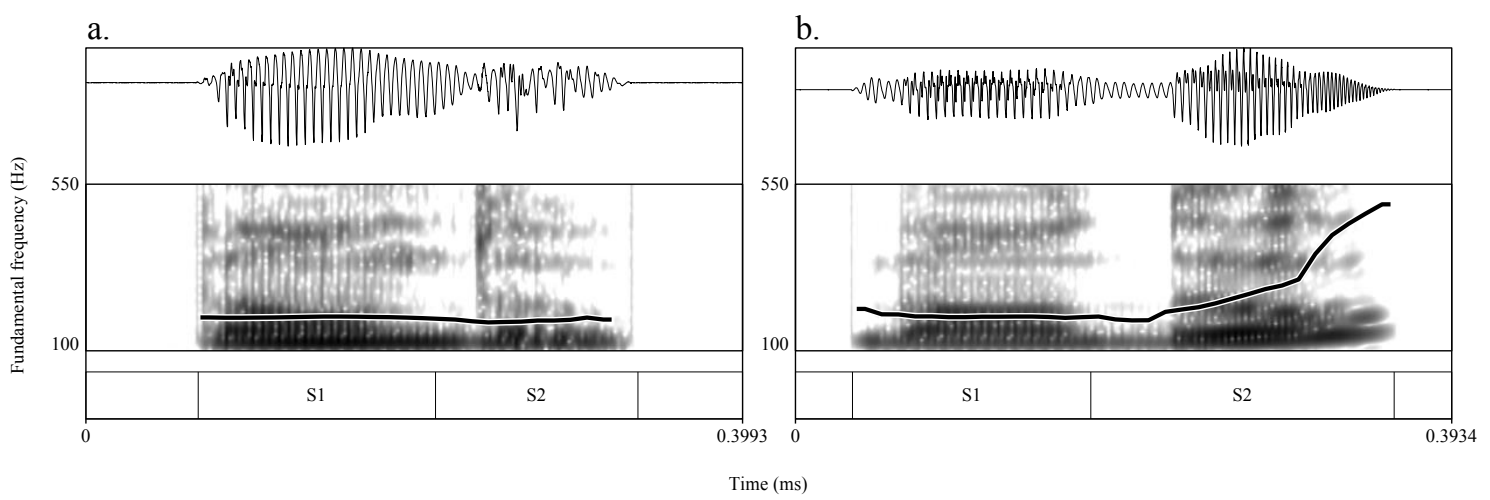


Figure 2. Mean Reaction Times (in ms) and Standard Errors as a function of prime type.

Percentage of correct responses is shown below the bar for each condition.

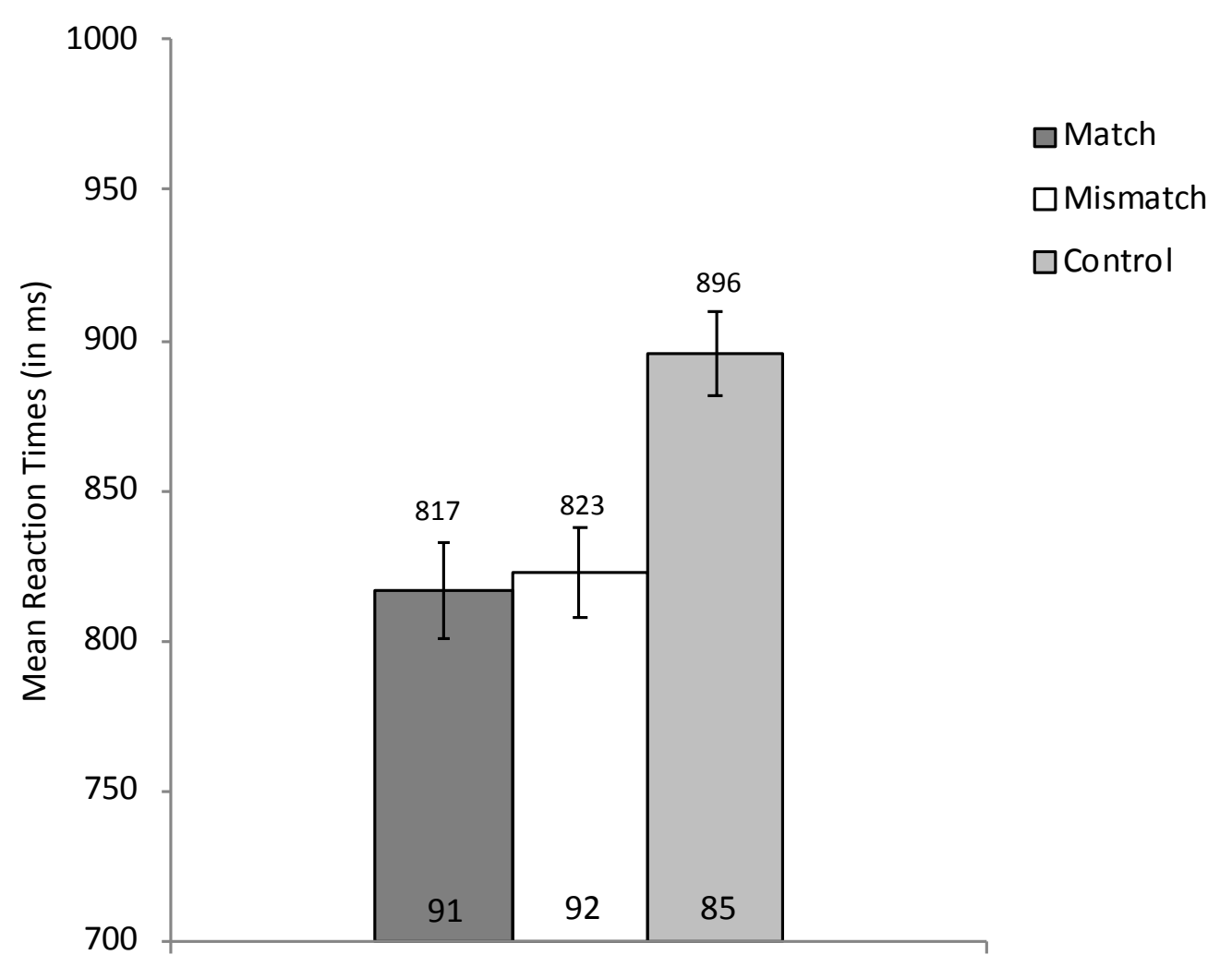


Appendix 1: Control primes and target words used in the experiment.

\begin{tabular}{|c|c|c|}
\hline $\begin{array}{l}\text { Control primes } \\
\text { baron } \\
\text { bijou } \\
\text { gamin } \\
\text { guenon } \\
\text { jambon } \\
\text { jumeau } \\
\text { melon } \\
\text { rubis } \\
\text { bilan } \\
\text { boudin } \\
\text { garant } \\
\text { jeudi } \\
\text { marron } \\
\text { relent } \\
\text { mairie } \\
\text { roseau }\end{array}$ & $\begin{array}{l}\text { Target words } \\
\text { bambou } \\
\text { diva } \\
\text { gala } \\
\text { levain } \\
\text { mamie } \\
\text { menu } \\
\text { robot } \\
\text { vallon } \\
\text { bonbon } \\
\text { donjon } \\
\text { juron } \\
\text { lundi } \\
\text { museau } \\
\text { remou } \\
\text { renom } \\
\text { vomi } \\
\text { bandeau } \\
\text { devis } \\
\text { landau } \\
\text { magie } \\
\text { magot } \\
\text { rabbin } \\
\text { regain } \\
\text { venin } \\
\text { bison } \\
\text { goulot } \\
\text { logis } \\
\text { malin } \\
\text { nougat } \\
\text { rameau } \\
\text { raisin } \\
\text { visa } \\
\text { boulon } \\
\text { bovin } \\
\text { gigot }\end{array}$ & $\begin{array}{l}\text { Target words continuation } \\
\text { lilas } \\
\text { morue } \\
\text { radis } \\
\text { roumain } \\
\text { renvoi } \\
\text { rouleau } \\
\text { bourreau } \\
\text { dindon } \\
\text { goujat } \\
\text { moulin } \\
\text { nounou } \\
\text { ravin } \\
\text { verrou }\end{array}$ \\
\hline
\end{tabular}


Appendix 2: Method and results of the control experiment.

\section{Method}

Participants: Thirty-six native speakers of French between 18 and 45 years old participated in the experiment. Each participant gave informed consent prior to the experiment. They all reported having no hearing or speech disorders. After running the experiment, we ensured through a reading task that all the participants pronounced the mid back rounded vowel as $/ \mathrm{J} /$ in closed syllables, as expected in the Southern French variety.

Material: Forty-two target words, whose /o/ vowel is pronounced [0] by Southern French speakers and [o] by Standard French speakers, were selected from Lexique (New et al., 2001) and were used both as primes and targets. Among the 42 target words, 14 were monosyllabic (e.g. mauve /mov/ 'mauve') and 28 were disyllabic with the critical vowel occurring on the last syllable (e.g. fantôme /fãtom/ 'ghost'). They had a mean frequency of 8.17 occurrences per million. 14 additional words of the same syllabic structure than the target words were selected and used as control primes. They had a mean frequency of 8.21 occurrences per million.

For the purpose of the lexical decision task, 56 pseudo-words with the same syllabic structure as the words were created by changing the last phoneme of real words not previously used (e.g. /gamim/ created from the word /gamin/ 'young girl').

A trained phonetician produced the 42 critical target words (e.g. mauve) in both their Standard (e.g. /mov/) and Southern (e.g. /mov/) French forms. All of the stimuli were recorded in 
a sound-attenuated room, digitized at a sampling frequency of $44100 \mathrm{~Hz}$, segmented and then normalized in intensity at a level of $70 \mathrm{~dB}$ SPL. The mean duration of the target words was $684 \mathrm{~ms}$ and $678 \mathrm{~ms}$ respectively in their Standard and Southern forms. The mean duration of the control words was $685 \mathrm{~ms}$.

Design: Two blocks of stimuli were presented. The first consisted of the primes and the second of the targets. The target block consisted of 42 target words and 42 pseudo-words. Among the 42 target words, 14 served in the matched priming condition, 14 in the mismatched priming condition and 14 in the control priming condition. Half the target words were presented in their Standard form, and the other half were presented in their Southern form. The prime block also consisted of 42 words and 42 pseudo-words. Among the prime words, 14 consisted in the repetition of the targets with the same /o/ variant (e.g. $/ \mathrm{mov} /-/ \mathrm{mov} /), 14$ consisted in the repetition of the targets with the different /o/ variant (e.g. $/ \mathrm{mov} /-/ \mathrm{mov} /$ ), and the other 14 were the control primes and were unrelated to the targets.

Because each target word was paired with three different primes (match, mismatch, control) and no participant was presented with the same target twice, three experimental lists were created. The three lists were then divided into two sub-lists so that the /o/ words in the prime and target blocks were heard both in their Standard and Southern French versions.

Procedure: It was the same as in the main experiment. 


\section{Results and discussion}

Statistical analyses were performed on the target words. One item that gave rise to an error rate of more than $40 \%$ was removed from the analyses. RTs analysis was performed on correct responses, thus removing 59 data (4\%) out of 1476 data. 3 outliers (RTs $>2500 \mathrm{~ms}$ ) were also excluded from the analysis. The mean RT and percentage of correct responses in each condition are presented in Figure 3. RTs were analyzed using a linear mixed-effect regression model, and a $\log$ transformation was applied to them. The model was run on 1414 data points. The model included prime type (match, mismatch, control) as fixed effect, participants and items as random intercepts and random slopes by participant and by item.

With the control prime condition as intercept, the model revealed that RTs were faster for target words preceded by match primes than for target words preceded by control primes $(\beta=$ $0.12, \mathrm{SE}=0.02, \mathrm{t}=-6.38, \mathrm{p}<.0001) . \mathrm{RTs}$ were also faster for target words preceded by mismatch primes than for target words preceded by control primes $(\beta=-0.09, \mathrm{SE}=0.01, \mathrm{t}=-6.15, \mathrm{p}<.0001)$. To test the difference between the match and the mismatch conditions, the model was releveled so that the match prime condition became the intercept. Crucially, a significant difference was observed between the match and mismatch prime conditions $(\beta=0.03, \mathrm{SE}=0.01, \mathrm{t}=2.10, \mathrm{p}<$ $.05)$, with RTs longer in the mismatch condition.

Accuracy data $(1=$ correct responses, $0=$ incorrect responses $)$ was analyzed using a mixedeffect regression model with a logistic linking function. The model was run on 1476 data points. It 
included prime type (match, mismatch, control) as fixed effect, participants and items as random intercepts and random slopes by participant and by item. No significant effect was found. 
Figure 3. Mean Reaction Times (in ms) and Standard Errors as a function of prime type. Percentage of correct responses is shown below the bar for each condition.

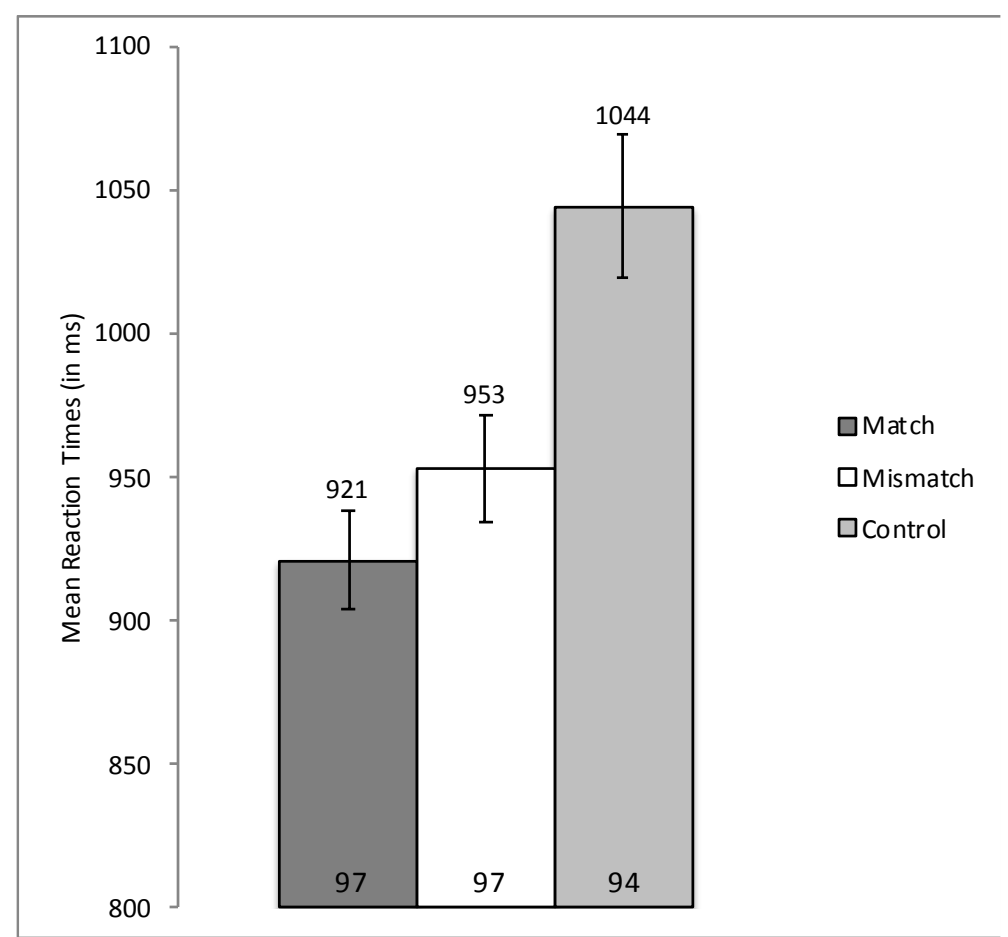




\section{Control primes and target words used in the control experiment}



